\title{
Claves de la experiencia religiosa en Aparecida: un aporte para la pastoral juvenil
}

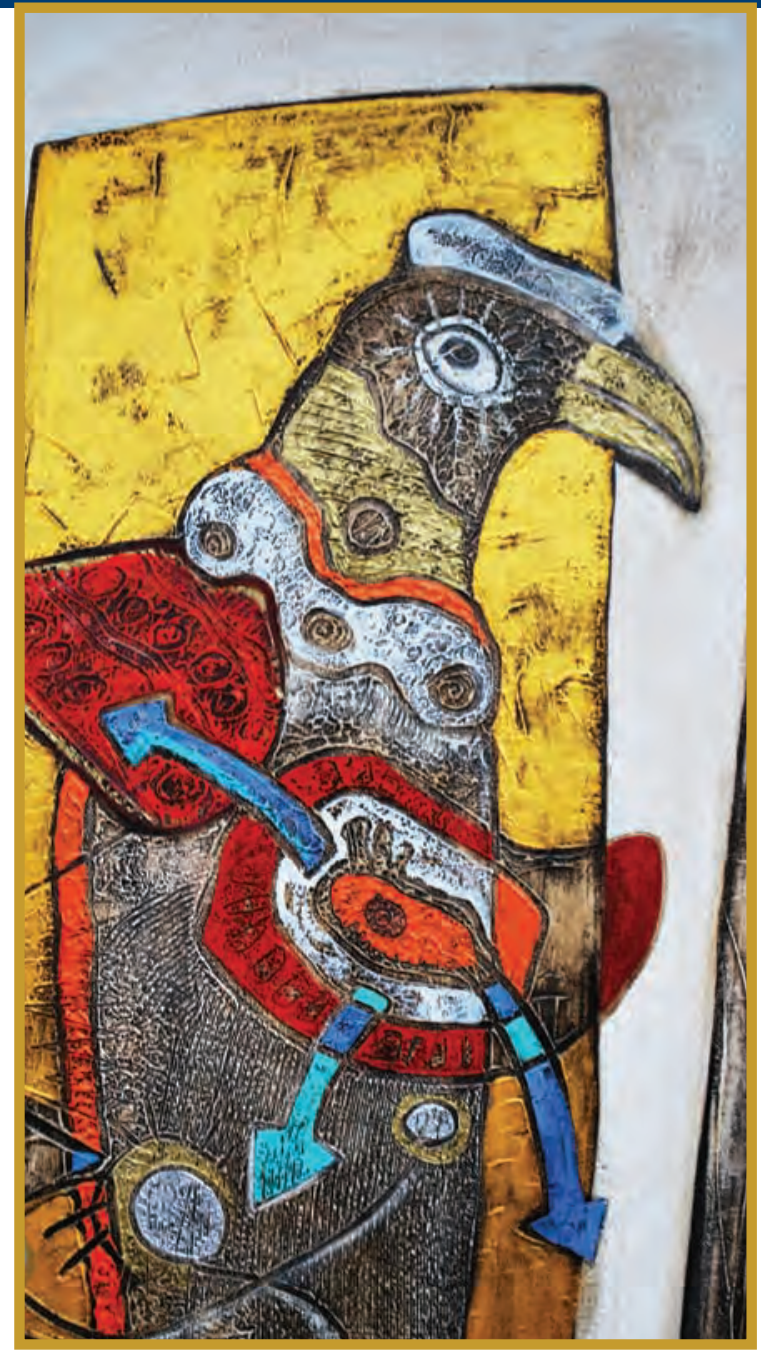

\section{Dra. Miriam Gallego*}

Para reflexionar sobre el tema de experiencia religiosa en el Documento de Aparecida es importante responder inicialmente a la pregunta: ¿qué entendemos por experiencia religiosa?

La palabra 'experiencia' deriva del verbo latino 'perior' y hace referencia a probar, tantear, atravesar, conocer algo. De este concepto se derivan las múltiples significaciones dadas a la palabra experiencia.

La palabra religiosa deriva del término religión e indica la palabra latina religare o re-legere y hace referencia a juntar, reunir, volver atar. En sentido amplio sería el conjunto de acciones encaminadas a 'volver a atar' a la humanidad después de haberse soltado de la Naturaleza.

Según A. Vergote, la experiencia religiosa, en primer lugar, es identificada como 'experiencia de lo sagrado', comprendido como conocimiento intuitivo estable y habitualmente accesible de una realidad sobrenatural presente al mundo y a las personas y que trasciende a ambos. En segundo lugar, como la 'captación profundamente afectiva' de una realidad sobrenatural que se revela como novedad que sorprende e interpela al hombre, transformándole duramente o pasajeramente, constituyendo un acontecimiento que sobreviene al hombre y da nuevo sentido a su vida. 
La experiencia religiosa, entonces es el 'encuentro personal' con la realidad en la cual se hace presente la dimensión del 'Misterio trascendente'. En este encuentro, interviene un conjunto de 'comportamientos y actitudes' de tipo cognitivo, sensitivo, afectivo etcétera. Tiene que ver con el sentido global de la existencia humana en cuanto concede fundamento al modo como existe el hombre y se encuentra en la realidad.

El contenido de experiencia religiosa de los jóvenes en Aparecida está estrechamente relacionado con la realidad sociocultural. De tal modo que la experiencia religiosa surge como sentido o falta de él en la situación concreta.

El tratamiento del tema se realiza a partir de dos preguntas concretas: $a$. ¿Cómo surge la experiencia religiosa en el Documento de Aparecida?; $b$. ¿Cuáles orientaciones se presentan para el trabajo con los jóvenes?

La reflexión a pesar de ser realizada en clave juvenil, no considera únicamente el ítem destinado a los jóvenes sino al documento como un todo y pretende ofrecer a los lectores pautas para el trabajo juvenil. Pues consideramos, que a la base de todo el documento se encuentra fuertemente arraigada una profunda orientación a la experiencia religiosa muy valiosa de rescatar para el trabajo de pastoral juvenil.

\section{1. ¿Cómo surge la experiencia religiosa en el Documento de Aparecida?}

Los medios de comunicación y su transformación son la primera señal que el documento presenta para hacer un acercamiento a la realidad sociocultural por la influencia en la colectividad: "La realidad social resulta demasiado grande para una conciencia que, teniendo en cuenta su falta de saber e información, fácilmente se cree insignificante, sin injerencia alguna en los acontecimientos, aun cuando suma su voz a otras voces que buscan ayudarse recíprocamente" (DA n. 36). Tal situación, lejos de llenar el vacío que en la conciencia se produce por la falta de un sentido unitario de la vida, en muchas ocasiones la información transmitida por los medios, es estimada como 'distractora': "La falta de información sólo se subsana con más información, retroalimentando la ansiedad de quien percibe que está en un mundo opaco y que no comprende" (ibíd., n. 38).

Por otro lado, la avidez del mercado, caracterizado por el 'consumismo', el documento la presenta como: "descontroladora del deseo de niños, jóvenes y adultos"; y a la 'publicidad' como conductora ilusoria de mundos lejanos y maravillosos, donde todo deseo puede ser satisfecho por los productos que tienen un carácter eficaz, efímero y hasta mesiánico; y, los deseos pueden ser pensados como felicidad; como sólo se necesita lo inmediato, la felicidad se dice que se pretende alcanzar con bienestar económico y satisfacción hedonista (ibíd., n. 50).

Las nuevas generaciones, afirma Aparecida, son las más afectadas por esta cultura del consumo en sus aspiraciones personales más profundas, consecuencia de ello es la acentuación de la lógica del individualismo pragmático y narcisista que les lleva a construir imaginarios especiales de libertad e igualdad: "las nuevas generaciones afirman el presente porque el pasado perdió relevancia ante tantas exclusiones sociales, políticas y económicas; participan de la lógica de la vida como espectáculo; consideran al cuerpo como punto de referencia de su realidad presente; tienen una nueva adicción por las sensaciones $y$, crecen en una gran mayoría sin referencia a los valores e instancias religiosas" (ibíd., n. 38). Para las nuevas generaciones, el futuro se presenta como incierto.

Frente a esta realidad mostrada como amenazante, el documento hace una relectura y evidencia los aspectos positivos de este cambio cultural enfatizando en "el valor fundamental de la persona, la subjetividad, la experiencia y la búsqueda del sentido de la vida y la trascendencia" (ibíd., n. 44. 36). 


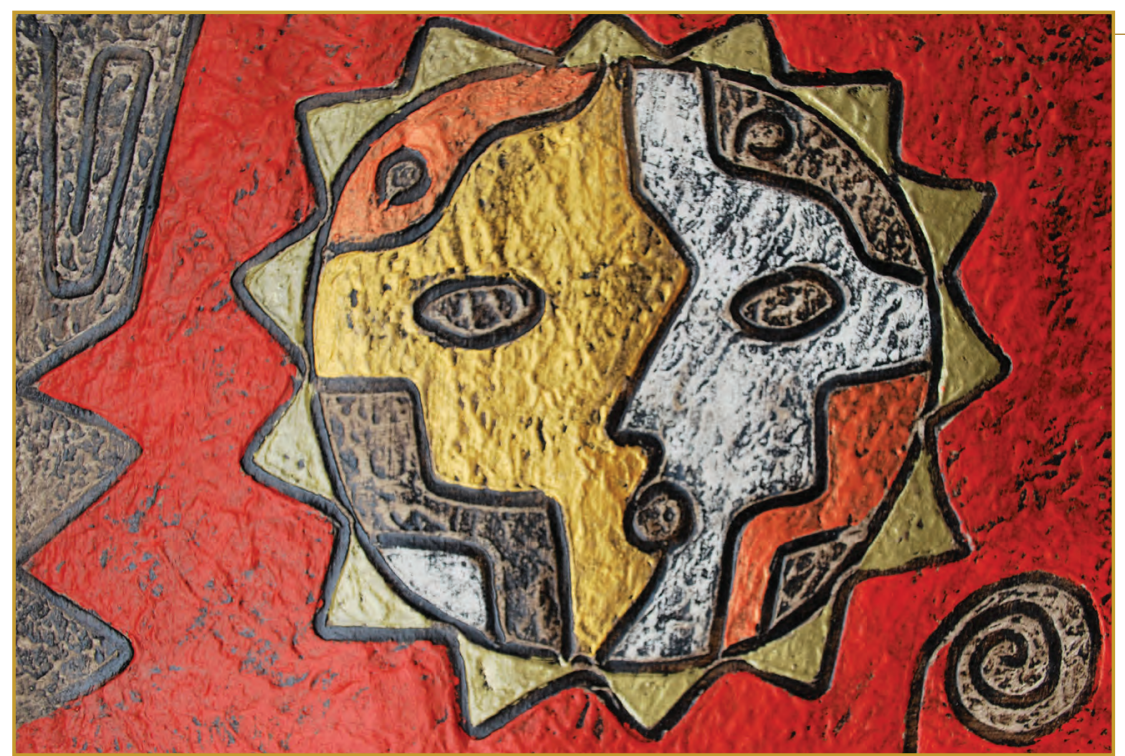

Ishkanti (Los dos)

Mixta 2010

Aparecida considera que: "el fracaso de las ideologías dominantes para dar respuesta a la búsqueda más profunda del significado de la vida, ha permitido que emerja como valor la sencillez y el reconocimiento en lo débil y lo pequeño de la existencia" (ibíd., n. 44). Asimismo considera que: "la necesidad de construir el propio destino y el anhelo de encontrar razones para la existencia, puede poner en movimiento el deseo de encontrarse con otros y compartir lo vivido como una manera de darse una respuesta. Se trata de una afirmación de la libertad personal $y$, por ello, de la necesidad de cuestionarse en profundidad las propias convicciones y opciones (ibíd., n. 53).

Este énfasis del aprecio de la persona abre nuevos horizontes para la comprensión del ser humano y el reconocimiento de Dios, ya que todo hombre abierto sinceramente a la verdad y al bien, aun entre dificultades e incertidumbres, puede llegar a descubrir en la ley natural escrita en su corazón (cfr. Rm 2, 14-15), el 'valor sagrado de la vida humana' desde su inicio hasta su término y, afirmar el derecho de cada ser humano a ver respetado totalmente este bien primario suyo (DA n. 108).

La experiencia religiosa entonces, aparece en el documento como portadora de 'sentido fundante' de la vida e historia humana. Ante una 'vida sin sentido', la experiencia religiosa revela la vida íntima de Dios en su misterio más elevado, la comunión trinitaria. Es tal el amor de Dios, que hace del hombre, peregrino en este mundo, su morada: "Vendremos a él y viviremos en él" (Jn 14, 23). Ante la 'desesperanza de un mundo sin Dios', que sólo ve en la muerte el término definitivo de la existencia, Jesús nos ofrece la resurrección y la vida eterna en la que Dios será da todo en todos (cfr. 1 Cor 15, 28). Ante la 'idolatría de los bienes terrenales', Jesús presenta la vida en Dios como valor supremo " ¿De qué le sirve a uno ganar el mundo, si pierde su vida?” (Mc 8, 36) - (DA n. 109).

En el Documento de Aparecida se reconoce que a las personas no les asusta la diversidad, sino más bien, lo que les asusta es no alcanzar reunir el conjunto de todos estos significados de la realidad en una comprensión unitaria que les permita ejercer su libertad con discernimiento y responsabilidad. La persona busca siempre la verdad de su ser, puesto que es esta verdad la que ilumina la realidad de tal modo que pueda desenvolverse en ella con libertad y alegría, con gozo y esperanza (ibíd., n. 42). Y en este sentido también los jóvenes son comprendidos como quienes no temen al sacrificio, ni a la entrega de la propia vida, pero si a una vida sin sentido (ibíd., n. 443).

La experiencia religiosa de este modo brota desde los imaginarios interiores del ser humano, y está muy estrechamente afectada con la experiencia de prioridad de la fe en Cristo. $\mathrm{Al}$ respecto, es interesante recordar las frases de Benedicto XVI expresadas en el discurso inaugural: "Ante la 'prioridad de la fe en Cristo y de la vida', ¿no podría ser acaso una fuga hacia el intimismo, hacia el individualismo religioso, un abandono de la realidad urgente de los grandes problemas económicos, sociales y políticos de América Latina y del mundo, y una fuga de la 
realidad hacia un mundo espiritual? ¿Qué es lo real? ¿Son 'realidad' sólo los bienes materiales, los problemas sociales, económicos y políticos? Cómo conocer realmente a Cristo para poder seguirlo y vivir con él, para encontrar la vida en Él, y para comunicar esta vida a los demás, a la sociedad y al mundo? Para el cristiano el núcleo de la respuesta es simple: "sólo Dios conoce a Dios, sólo el hijo que es Dios de Dios, Dios verdadero, lo conoce. De aquí la importancia única e insustituible de Cristo para nosotros, para la humanidad" (ibíd., n. 3).

La experiencia religiosa según Aparecida, surge principalmente desde la realidad de la que es partícipe el ser humano, puesto que: "la persona humana es en su misma esencia, aquel lugar de la naturaleza donde converge la variedad de los significados en una única vocación de sentido" (ibíd., n. 42); de allí confluye la tarea evan- gelizadora de la Iglesia: el anuncio de Jesucristo como el Señor de la Vida.

La prioridad de de la fe en Cristo y de la Vida, según Aparecida, es el elemento principal en la experiencia religiosa. Pues, el hecho religioso, se antepone a los hechos sociales, no para intimidarlos o separarlos, sino para comprender a partir de la realidad del Misterio, el sentido y significado, no sólo de las cosas en cuanto a situaciones externas, sino al hombre en sí mismo: "Sólo quien reconoce a Dios, conoce la realidad y puede responder a ella de modo adecuado y realmente humano" (DA n.3, Benedicto XVI, DI), de igual forma: "Quien excluye a Dios de su horizonte falsifica el concepto de realidad y, en consecuencia, sólo puede terminar en cambios equivocados y con recetas destructivas" (ibíd).

De esta manera, la experiencia religiosa identificada en el documento, trata de confirmar,

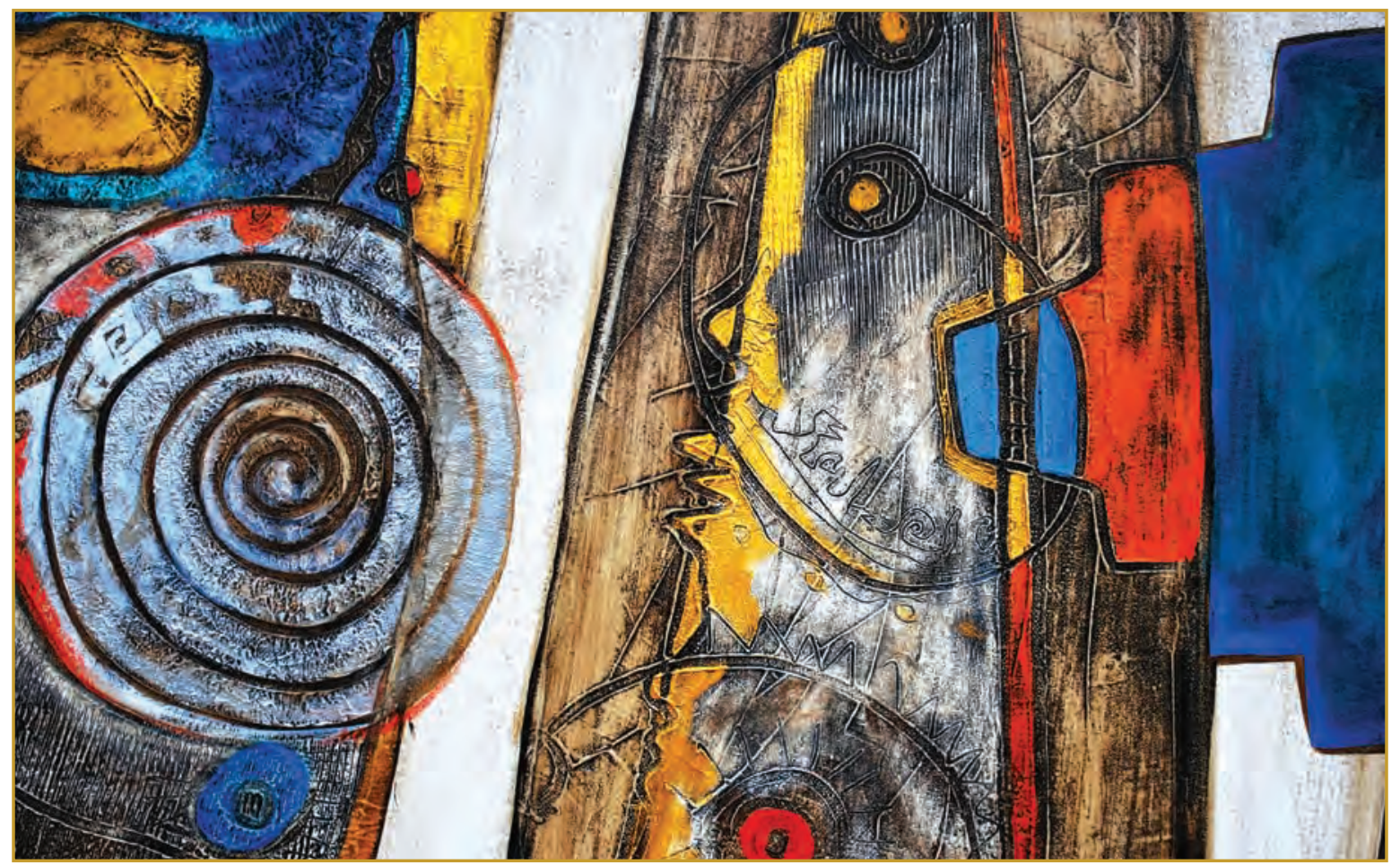

Kawsay-wañuy (Vida-muerte)

Mixta 2010 
renovar y revitalizar la novedad del Evangelio arraigada en nuestra historia, desde un encuentro personal y comunitario con Jesucristo, para llegar a ser discípulos y misioneros" (DA n. 11b, Introducción). Así el documento afirma que es necesario que los jóvenes experimenten, que no siguen a un personaje de la historia pasada, sino, a Cristo vivo, presente en el hoy y ahora de sus vidas; que lo descubran como el viviente que camina a su lado, desentrañando el sentido de los acontecimientos, del dolor y de la muerte, de la alegría y de la fiesta; que lo adviertan como el dueño de la casa que les invita a entrar y a permanecer en ella, alimentándoles con el Pan que da la vida. (DA n. 4, Benedicto XVI, DI).

A más de la atención que Aparecida presta a la comprensión de la experiencia religiosa interior, manifiesta que la experiencia religiosa dentro de la vida cristiana puede llegar a tener un sentido verdadero sólo si se profundiza y se desarrolla en la 'comunión fraterna'. Ante la 'despersonalización', Jesús ayuda a construir identidades integradas. (DA n. 110). Jesús nos dice "uno es su maestro, y todos ustedes son hermanos" (Mt 23, 8). De allí que hace un llamado a reforzar en la práctica pastoral 'la experiencia religiosa' insistiendo que la Iglesia debe ofrecer a los fieles un 'encuentro personal con Jesucristo', un profundo compromiso con los hermanos, un anuncio kerigmático y un coherente testimonio de los evangelizadores que lleve a una conversión personal y a un cambio de vida integral (DA n. 226). Para esto, es importante que la experiencia religiosa parta de la 'centralidad del hombre' ya que es en sí mismo sujeto de la experiencia, sin dejar de lado el sentido comunitario.

\section{2. ¿Cuáles orientaciones pastorales?}

Dentro de las orientaciones pastorales que el documento presenta para fortalecer la experiencia religiosa en los jóvenes pone énfasis en 'la vida y su existencia'. Por tanto, es necesario pre-

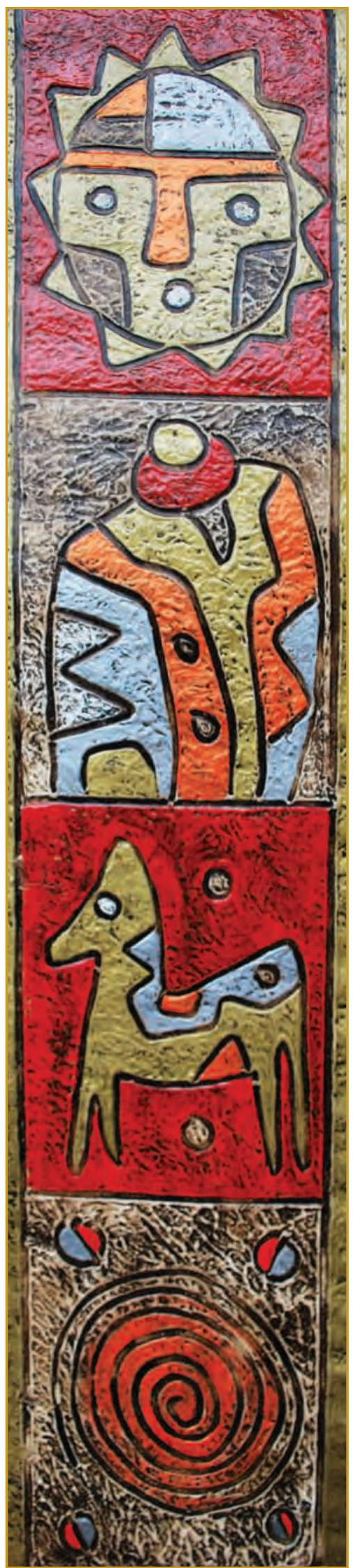

Nuka (Yo)

Mixta 2010 


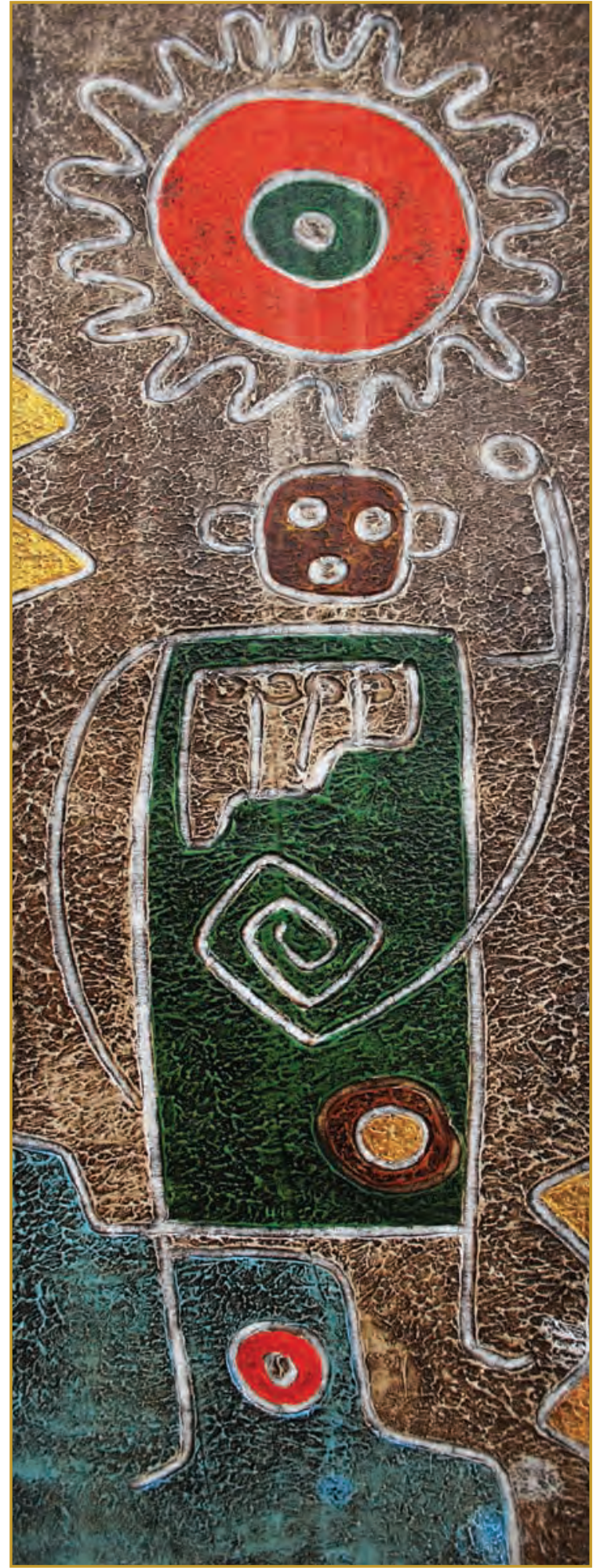

Yuyaykuna (Ideas)

Mixta 2010 sentar la vida humana como el centro de la vida social y cultural, resaltando en ella, la dignidad de ser imagen y semejanza de Dios y la vocación a ser hijos en el Hijo, llamándonos a compartir su vida por toda la eternidad (ibíd., n. 480). A partir de esta categoría se exponen algunas indicaciones para la pastoral:

- En primer lugar el documento hace referencia a las 'tradiciones culturales ceñidas por una profunda religiosidad popular'. Entre ellas se señalan: las fiestas patronales, las peregrinaciones, las novenas, rosarios, vía crucis, procesiones, danzas, los cánticos del folclore religioso, el cariño a los santos y a los ángeles, las promesas, las oraciones en familia (ibíd., n. 37, 446, 549). De este grupo de prácticas se destacan las peregrinaciones que representan al Pueblo de Dios en camino.

En las peregrinaciones el joven celebra el gozo de sentirse inmerso en el camino hacia Dios, en medio de tantos hermanos. La decisión de partir hacia un santuario ya es una confesión de fe, el caminar es un verdadero canto de esperanza, y la llegada es un encuentro de amor. La mirada del peregrino joven se deposita sobre una imagen que simboliza la ternura y la cercanía de Dios. La súplica sincera, que fluye confiadamente, es la mejor expresión de un corazón que ha renunciado a la autosuficiencia, reconociendo que solo nada puede. En un breve instante condensa una viva experiencia espiritual (ibíd., n. 259). En los santuarios muchos peregrinos toman decisiones que marcan sus vidas. Esas paredes contienen muchas historias de conversión, de perdón y de dones recibidos que millones podrían contar (ibíd., n. 92,93).

La piedad popular penetra delicadamente la existencia personal de cada joven y aunque también se vive en una multitud, no es una 'espiritualidad de masas'. En distintos momentos de la lucha cotidiana, muchos recu- 


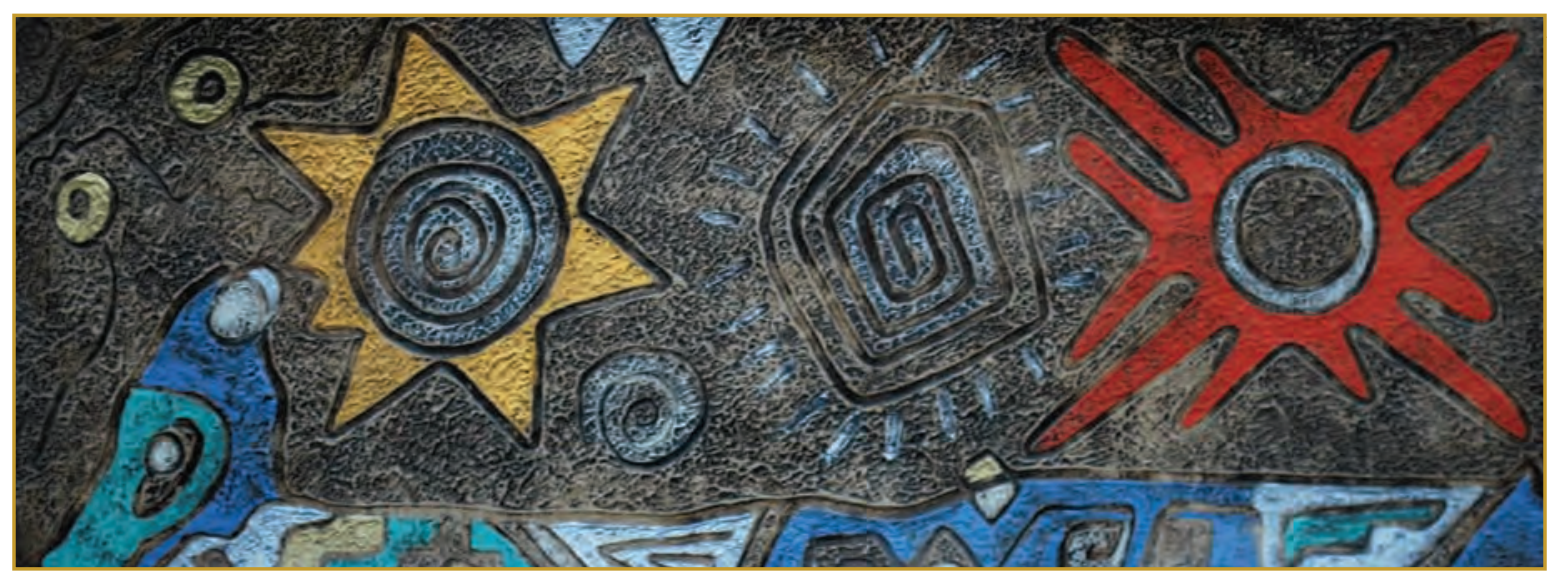

Kuyllurkuna (Estrella)

Mixta 2010

rren a algún pequeño signo del amor de Dios, como a un crucifijo, un rosario, una vela que se enciende para acompañar a un ser querido en su enfermedad, un Padrenuestro musitado entre lágrimas, una mirada entrañable a una imagen querida de María, una sonrisa dirigida al Cielo en medio de una sencilla alegría. (ibíd., n. 261).

Aparecida, después de la valoración acerca de esta experiencia religiosa ceñida por una profunda religiosidad popular reconoce que hoy en día tales tradiciones ya no se transmiten de una generación a otra con la misma fluidez que en el pasado, y que ello afecta, incluso, a ese núcleo más profundo de cada cultura, constituido por la experiencia religiosa, que resulta ahora igualmente difícil de transmitir a través de la educación y de la belleza de las expresiones culturales, alcanzando aun hasta la misma familia que, como lugar del diálogo y de la solidaridad inter-generacional, había sido uno de los vehículos más importantes de la transmisión de la fe (ibíd., n. 39a).

Al lado de la sabiduría de las tradiciones, el documento dice que ahora se ubica en competencia, la información de último minuto, la distracción, el entretenimiento, las imágenes de los exitosos que han sabido aprovechar en su favor las herramientas tecnológicas y las expectativas de prestigio y estima social. Ello hace que los jóvenes busquen animosamente una experiencia de sentido que llene las exigencias de su vocación allí donde no podrán jamás encontrarla (ibíd., n. 39b).
- En segundo lugar se hace referencia a 'la naturaleza' como medio para educar al encuentro de los jóvenes con Dios. La naturaleza, por ser portadora de gran significado, es una de las mejores formas a través de la cual orientar a los jóvenes al encuentro con Dios, así, como también, es una señal visible para emprender un camino que con lleve al trascendente. Esta experiencia con la naturaleza debe llevar a lo que Pablo dice, recapitular todas las cosas en Cristo y de alabar con Él al Padre (cfr. 1 Cor 3, 21-23). (ibíd., n. 126, 110).

- En tercer lugar, se presenta la 'palabra de Dios' como medio fundamental para desarrollar la experiencia religiosa (DA n. 3, Benedicto XVI, DI). A través de la palabra los jóvenes no sólo son introducidos a la experiencia religiosa, sino también a saber dar nombre a las situaciones concretas de la vida y a llamar con un nombre específico el misterio trascendente revelado en la experiencia: Jesucristo. "Hay que educar a los jóvenes en la lectura y meditación de la 'palabra de Dios'; que ella se convierta en alimento para que, por propia experiencia, vean que las palabras de Jesús son espíritu y vida (Jn 6,63). De lo contrario, ¿cómo van a anunciar un mensaje cuyo contenido y espíritu no conocen a fondo?" (DA n. 3, Benedicto XVI, DI). Se ha de fundamentar de esta manera el compromiso misionero y toda nuestra vida en la roca de la Palabra de Dios (DA n. 247). 
Por otro lado, no se concibe que se pueda anunciar el Evangelio sin que éste, ilumine, infunda, dé aliento, nutra la esperanza e inspire soluciones adecuadas a los problemas de la existencia; ni tampoco que pueda pensarse en una verdadera promoción del ser humano sin abrirlo a Dios y anunciarle a Jesucristo (ibíd., n. 333); así como dejando de lado las realidades sociales y comunitarias.

\section{Valoración}

El tema de la experiencia religiosa en el documento de Aparecida de esta forma, hace referencia a la experiencia de fe, en un encuentro personal con Jesucristo. A pesar de que el punto en el que converge tal dimensión es 'la vida misma en su situación y realidad concreta', las orientaciones pastorales parecen dejar de lado este aspecto.

Creemos que es importante "capacitar al joven a construirse a sí mismo como persona, al interno de una aventura de búsqueda de sentido y significado. Para esto es importante:

1. Ayudar a los jóvenes a descubrir la propia individualidad desde una valoración personal, existencial y social. Esto ayuda a superar, por un lado, el riesgo de que los jóvenes vengan considerados de una forma grupal o comunitaria, en cuanto participan y actúan en 'acciones concretas'; y, por otro, que vengan apreciados únicamente en cuanto la pastoral juvenil, a través de ellos, puede alcanzar sus objetivos.

2. El orden de la naturaleza y del universo es una invitación constante a combatir el desorden y el caos que reinan en el alrededor, y cuyo protagonista es el mismo hombre. Para esto es importante ayudar a restituir, en los jóvenes, el sentido y el valor del lenguaje simbólico; y que, en la naturaleza, se ofrece de manera gratui- ta y significante e imposible de agotar. Dentro de esta contemplación y valorización del lenguaje simbólico, se puede aprovechar de manera peculiar la belleza física humana.

3. La mayoría de los jóvenes se acerca a la realidad, ya sea a su propia vida o al ambiente social o a la naturaleza, a través de unos modelos y criterios ambientalmente impuestos. Las relaciones sociales cotidianas aparecen, cada día más, en función de la producción y el consumismo y la vida personal de cada uno se debate entre la novedad y el deseo de sobresalir, aun a costa de vivir en la apariencia o imponiéndose a los otros. La vida interior, caracterizada por la historia personal concreta, no resulta -en la mayoría de los casos- un recurso para explorar y descubrir el gran valor, más bien, se la ve como una amenaza a la construcción de la identidad personal y humana. Sin embargo, la vida interior de cada uno, con una historia de vida concreta, caracterizada por lo cotidiano, contiene un sentido profundo e importante por descubrir.

4. La experiencia religiosa, por su parte, considera al lenguaje como un elemento cualificante de su desarrollo. El lenguaje religioso es una categoría fundamental en la experiencia religiosa. Pues, tanto el hombre -sujeto de relación- como Dios-objeto de experiencia- necesitan de medios para hacerse presentes. De allí la importancia de descubrir y resinificar los signos y símbolos juveniles.

La pastoral juvenil así, encuentra en la vida de los jóvenes espacio favorable para el encuentro con Dios, con el trascendente, con Jesucristo. En su búsqueda del sentido de la vida, pueden ser educados a ser y descubrir el llamado particular que el Señor Jesús les hace para ser discípulos y testigos del encuentro con Cristo (ibíd., n. 443). 